\title{
Mundos virtuais e identidade social: processos de formação e mediação através da lógica do jogo
}

José Carlos Ribeiro

Professor Doutor do Programa de Pós-graduação em Comunicação e Cultura Contemporâneas da Facom/UFBa. Pesquisador do Grupo de Pesquisa em Cibercidades (GPC) / Ciberpesquisa. Professor Adjunto do Departamento de Psicologia (UFBA).

Email: jcsr01@gmail.com.

Thiago Falcão Aluno do Curso de Mestrado do Programa de Pós-Graduação em Comunicação e Cultura Contemporânea da Universidade Federal da Bahia. Membro do Grupo de Pesquisa em Cibercidades (GPC) / Ciberpesquisa. Email: falc4o@gmail.com.

\section{Resumo:}

O presente artigo pretende discutir o processo de formação de identidades sociais online nos 'mundos virtuais' - nossa hipótese é a de que a presença do que Salen e Zimmerman (2003) chamam de 'círculo mágico’ exerça uma força mediadora que singulariza o processo de criação de identidades sociais, de modo a tornar tal particularização algo digno de atenção pelos estudos da cibercultura.

Palavras-chave: Cibercultura, Mundos Virtuais, Identidade Social.

\begin{abstract}
:
This paper aims at discussing the process of online social identity construction and how it is presented in virtual worlds. We posit, basically, that the presence of what is called magic circle by Salen and Zimmerman (2003) exerts a mediating power by transforming the social identities conception process, attaching it to the dynamics imprinted by the game structure present in such worlds.
\end{abstract}

Keywords: Cyberculture, Virtual Worlds, Social Identity. 


\section{Da Essência do Jogar}

É curioso perceber que existe um tipo de acordo no que se refere ao enquadramento utilizado pelos vários aspectos da mídia de se referir, comumente, ao ato de trabalhar e ao de jogar/brincar como dois pólos distintos de uma mesma dicotomia. Tal enquadramento tem, ao longo da história, recebido o apoio - sob a forma de argumentação - de vários teóricos clássicos dos estudos dos jogos: Huizinga (1950) e Caillois (1961), por exemplo, acreditavam que para jogar, o indivíduo precisava conscientemente se desligar de sua vida 'normal' e adentrar uma atividade considerada 'não séria' - assumindo uma supressáo do espaço-tempo. Esse suposto lugar no espaço-tempo no qual a atividade lúdica se desenvolve recebeu uma terminologia - e um tratamento mais cuidadoso - quando, em 2003, Salen e Zimmerman publicaram seu tratado de desenvolvimento e análise generalista dos processos pelos quais o jogo se dá desde seu suporte analógico, representado comumente por cartas e tabuleiros, à hipermídia, onde se encontra a essência do game - e passou a ser chamado de 'círculo mágico'1, sendo inspirado em uma passagem do clássico Homo Ludens, de Huizinga (1950).

Embora o círculo mágico seja meramente um dos exemplos de 'lugares de jogo' listados
por Huizinga, o termo é usado aqui como um atalho para a idéia de um lugar
especial criado por um jogo no tempo e no espaço. O fato de que o círculo mágico é só
isso - um círculo - é uma característica importante deste conceito. Como um círculo
fechado, o espaço que ele circunscreve é encapsulado e separado do mundo real. Como
um marcador de tempo, o círculo mágico é como um relógio: ele simultaneamente
representa um caminho com um começo e fim, mas sem começo e fim. O círculo mágico
inscreve um espaço que é repetivel, um espaço limitado e sem limite ao mesmo tempo.
Resumindo, um espaço finito, compossibilidades infinitas (SALENe ZIMMERMAN,
2003, p. 95).

O conceito de Salen e Zimmerman, embora de certa forma fundamentado em um dos mais clássicos tratados sobre a relação entre cultura e expressão lúdica, tem sido extensamente discutido nos últimos anos. Tal idéia, sugerida como enquadramento padrão tanto pela mídia quanto por instituiçóes sociais de grande representação (como a família), vem, a cada dia, encontrando cada vez menos bases nas quais poderia se apoiar.

Por outro lado, é através de Salen e Zimmerman (2003, p. 96) que podemos construir melhor o argumento que nos leva a um entendimento diferenciado do conceito de 'círculo mágico'. Os autores, na dada passagem, discutem sobre a existência hipotética de um tabuleiro de gamão - que serve meramente para enfeitar a mesa de uma casa qualquer - mas que eventualmente é ocupado por jogadores, e tem, assim, sua função modificada de simples item de decoração para dispositivo de entrada - e aqui evocamos a idéia da imersão, que há de ser tratada mais à frente - ou de transporte para outra realidade:

O tabuleiro de gamão se torna um espaço especial que facilita o ato de jogar o jogo. A atenção dos jogadores transfere-se completamente para o jogo, que media sua interação através da jogabilidade. Enquanto o jogo estiver em progresso, os jogadores não vão rearranjar as peças 
casualmente, e sim movê-las de acordo com regras muito particulares (SALEN e ZIMMERMAN, 2003, p. 96, grifo nosso).

Vale retornar ainda à idéia de transposição entre realidades sustentada por Salen e Zimmerman (2003, p. 97): “O que significa decidir jogar um jogo? Se o 'círculo mágico' cria uma realidade alternativa, que atitudes psicológicas são necessárias de um jogador que se encontra no momento de adentrar um jogo?". Se contextualizarmos de forma mais sólida dentro do universo dos games que é inerente ao universo imaginário da cibercultura - saindo um pouco da abstração dos jogos de tabuleiro e desse modelo clássico proposto pelos autores aqui trabalhados -, tal afirmativa pode ser considerada uma alusão à ultrapassada dicotomia realidade-ciberespaço, que foi posta em xeque pelas teorias da cibercultura já há algum tempo (cf. LEMOS, 2007b).

Mas é realmente válido falar de uma barreira entre realidades, ou entre realidade e jogo que precisa ser rompida? Talvez sim, ao considerarmos games nos quais a essência da linha narrativa se faz mais perceptiva que a essência das regras (num retorno à antiga discussão narratologia versus ludologia, tão cara aos estudos dos jogos), como por exemplo em Silent Hill ${ }^{2}$, nos quais exista a necessidade de lidar com experiências sensitivas particulares, o que vem a pressupor completa absorção do jogador no jogo; usaremos aqui o termo imersão para endereçar tal fenômeno, de acordo com Murray (1999).

O mesmo já não pode ser dito quando nos endereçamos a outras categorias de jogos, como os pervarsive games, os alternate reality games (ARGs) e os MMORPGs. Os primeiros acontecem em zonas híbridas entre materialidade e informação, com seu desenrolar necessariamente se dando tanto no pólo da realidade quanto no ambiente de jogo, que é o ambiente urbano experimentado e vivenciado tanto por jogadores (de maneira lúdica) quanto por transeuntes momentâneos (de maneira não lúdica) - como no jogo Cruel $2 \mathrm{~B} \mathrm{Kind}{ }^{3}$, analisado anteriormente por Ribeiro, Brunet e Falcão (2008). Os alternate reality games (ARGs), por sua vez, insistem no fato de que não são um jogo e que os jogadores adeptos a tais expressóes lúdicas transitam entre ficção e realidade sem conseguir uma distinção precisa e categórica do que é e do que não é dentro dos procedimentos e tarefas sugeridas nas missóes. Por fim, e de maior articulação com as propostas reflexivas deste trabalho, os MMORPGs ${ }^{4}$, que atualmente se dissociam pela cultura e se tornam não só veículos de entretenimento, mas ferramentas de trabalho usadas para os mais diversos fins, desde funcionando necessariamente como ambiente para pesquisas científicas (BAINBRIDGE, 2007), passando por especulação imobiliária de ambientes virtuais (vide o caso da alemã Anshe Chung 5 em Second LifeG) até a apropriação e o desenvolvimento de novas práticas relacionadas ao trabalho, como a prática de gold farming (DIBBEL, 2007; HEEKS, 2008; FALCÃO, 2008).

É importante frisar que o objetivo do presente trabalho não é desmerecer o conceito trabalhado por Salen e Zimmerman (2003), mas reconsiderá-lo a partir da premissa de que algumas formas lúdicas assumiram, com o passar do tempo e devido ao seu contato para com as tecnologias digitais e telemáticas, estruturas complexas que o formalismo e o generalismo de Huizinga 
(1950) e de Caillois (1961), bem como o conceito de Salen e Zimmerman (2003) não conseguem mais encapsular. Assim sendo, questionamos não a totalidade do conceito do 'círculo mágico' - cujo entendimento clássico associado ao processo de imersão é vital para o desenvolvimento do presente artigo -, mas principalmente sua aplicação a esses casos fronteiriços, nos quais fica claro que há um diálogo muito maior da estrutura do jogo com a realidade.

Retornando à citação de Salen e Zimmerman (2003) mencionada, a idéia principal não seria então, a de necessariamente encapsular o sujeito, suprimir-lhe o espaço-tempo e projetar-lhe numa zona alternativa. Melhor que isso talvez fosse considerar que o 'círculo mágico' existe sim - e é inerente à estrutura do jogo - mas como fator mediador, que auxilia no diálogo do jogador para com o jogo e a realidade. Trabalhando no processo de relacionamento do homem para com o duo jogo/real, essa mediaçáo pode se apresentar tanto de forma fluida, desenhando fronteiras que se mostrem borradas (não plenamente identificadas), que permitam que ficção e realidade se encontrem, quanto de forma mais sólida, realmente fazendo com que o usuário/jogador experimente um sentimento de deslocamento, supressão espaço-temporal através de um processo de imersão, conforme vamos sugerir em um tópico mais adiante.

A partir de agora, trataremos de uma melhor definição do objeto escolhido, com o intuito de prosseguir com a argumentaçáo proposta.

\section{"Mundos Virtuais": Híbridos entre Jogos Eletrônicos e Comunidades Virtuais}

"Mundos virtuais" são ambientes multiusuário, navegáveis espacialmente através de um avatar e mediados por computador que, apesar de deverem muito de sua lógica aos MUDs ${ }^{7}$, funcionam hoje como sua evolução, portando gráficos potentes, mitologias complexas e uma capacidade de receber milhóes de jogadores no sistema de forma simultânea.

Para que esse conhecimento se apresente de forma mais visível, precisamos transitar por entre algumas definiçóes e reflexóes associadas aos elementos que aqui se relacionam - games, comunidades virtuais e 'mundos virtuais' que vão nos levar a uma contextualização mais sólida, para que seja possível identificar o objeto específico no qual escolhemos trabalhar, quando abordando a questão do processo de formação de identidade e sua relação com a comunicação mediada por computador (CMC).

Objetivamente, um 'mundo virtual' é um ambiente simulado baseado na interação via computador, no qual os usuários 'habitam' estes espaços através de seus avatares. A metáfora da habitação é aqui apoiada sobre um conceito que a própria Klastrup (2003a) discute em sua tese, mas que será enfocado um pouco à frente no presente trabalho - o conceito de worldness. Tal 'habitação', continuando, geralmente é mediada através de uma representação na forma de figuras humanóides que podem ser desenhadas tanto em $2 \mathrm{D}$ quanto em $3 \mathrm{D}^{8}$. 
Um mundo virtual é uma representação persistente online que contém a possibilidade de comunicação sincrona entre usuários, e entre usuário e mundo dentro de uma estrutura espacial desenhada como um universo navegável. "Mundos virtuais" são mundos nos quais se pode navegar através de representaçôes persistentes do usuário, ao contrário de mundos imaginados de ficçóes não-digitais, os quais são apresentados como habitados, mas não são realmente habitáveis. Mundos virtuais são diferentes de outros ambientes virtuais porque não podem ser imaginados em toda sua totalidade espacial (KLASTRUP, 2003a, p. 26).

Uma série de apropriaçóes da tecnologia telemática desenvolvida entre a década de 1960 e 1990 guarda, em sua essência, os primeiros traços que ensejam a construção de 'mundos virtuais' como aqui os referenciamos. Desde as primeiras experiências comunitárias efetivadas através das famosas BBSs (Bulletin Board Systems), passando pelos tópicos de discussão específicos da Usenet, e pelos diversos chats (salas de bate-papo, web-chats, chats gráficos etc.), até os MUDs e os sites de promoção de relacionamentos sociais, o que se observa é a gradativa sofisticação destes ambientes e mundos narrativos ficcionais, tanto no que se refere às tecnologias comunicacionais empregadas quanto aos processos de sociabilidade adotados, conforme apontamentos efetuados por diversos autores (TURKLE, 1997; MURRAY, 1999; ALVES, 2005; dentre outros).

A preocupação da autora está principalmente associada à criação da experiência presencial num 'mundo virtual'. Baseando-se em questóes do tipo: "Como você descreveria a experiência de 'estar lá' ou a experiência de habitar o 'mundo virtual?", "O que cria essa experiência?" ou "Como podemos interpretar o que acontece quando você está lá dentro?”, ela tenta, então, desenvolver uma poética dos 'mundos virtuais', que se ocupa principalmente de definir o que faz de um 'mundo virtual' um 'mundo virtual' experienciado - ou seja, busca sua essência. Essa seria a idéia que a palavra worldness transpareceria, quando associada a tal teoria.

Fica claro que a maneira como este mundo é percebido torna-se parte fundamental na sua composição, uma vez que é através destes processos de (re) leitura e de (re) configuração dos elementos narrativos, propiciados pelos dispositivos técnicos possíveis de serem utilizados nos ambientes (variáveis técnicas), e das demandas individualizadas dos jogadores (variáveis psicossociais), é que o 'mundo virtual' vai adquirindo o formato de ambiência imersiva.

\section{Através do Espelho: A Imersão}

Os jogos eletrônicos funcionam, nos dias de hoje, como dispositivos que portam uma carga de informação que é reconhecida como força (inter) ativa no processo de produçáo de sentido desenvolvido pelo usuário/jogador no momento em que este 'experimenta' a história contada - o texto, na verdade, composto por regras e ficção (KLASTRUP, 2003a, JUUL, 2005). O grande mérito de tais games encontra-se na alçada da imersão. Enquanto os meios de reprodução tradicionais, como o cinema e a televisão, clamam por uma imersão passiva, onde o leitor simplesmente absorve o que é transmitido e a 
interação é praticamente condensada ao ato da interpretação pessoal, o game transpóe esse processo para um diferente patamar, onde a imersão se dá de forma muito mais palpável.

Retornando à argumentação do presente artigo, acreditamos que a idéia sugerida - de que há uma gradação nas fronteiras estabelecidas pelo 'círculo mágico' nos 'mundos virtuais' - esteja intimamente ligada à sensação experimentada quando do processo de imersão, de forma progressiva: as fronteiras do 'círculo mágico' se definem, se 'solidificam' à medida que o processo de imersão se desenvolve, à medida que uma realidade parece se transformar em outra, à medida que 'atravessamos o espelho'.

Klastrup (2003a), que defende a idéia do hibridismo dos 'mundos virtuais', possui uma visão complementar ao modelo rapidamente proposto, e que nos parece razoável: para a autora, a imersão nos ambientes virtuais estudados é apenas um elemento tangente à composiçáo de toda uma poética ${ }^{9}$; esta por sua vez sendo composta por (1) um modelo de produção de sentido baseado em uma textualidade produzida por múltiplos usuários e (2) uma grade analítica com o intuito de estudar os agentes, as formas de interação, amplitude da interação e interação-emtempo, esta última possibilitando a emergência de uma história (um evento que pode ser narrativamente relatado, mas que não possui necessariamente ligação com o cerne narrativo que ampara o mundo em questão).

A autora acredita que os dois tópicos acima são essenciais para que o usuário/jogador desenvolva um relacionamento com o mundo, fazendo com que ele deseje retornar; tais requisitos ajudariam a criar uma essência de mundo (worldness) específica, além de ajudar o sujeito a produzir experiências que possam satisfazer a comunidade da qual ele faz parte.

Dada, então, tal particularidade no processo de imersão em 'mundos virtuais', no qual tal ilusão de mundo seria reforçada pela necessidade da interação e navegação, Klastrup (2003a) segue apontando que talvez seja mais produtivo expandir tal conceito. A autora faz isso com base no conceito de Ryan, que classifica imersão como sendo "a experiência através da qual um mundo fictício adquire a presença de uma realidade autônoma e independente de linguagem, populada por seres humanos vivos" (RYAN, 2001, p. 15). Para simplesmente se defender de uma assunção baseada no senso comum, no qual 'imersão' geralmente se refere a um processo de sedução passiva por meio da linguagem de um veículo - especialmente no caso de portadores do modelo narrativo tradicional -, Klastrup (2003a) sugere que talvez seja o caso de falarmos de 'presença e relacionamento' (presence and engagement) - que são conceitos que se encaixam de forma melhor para representar a experiência de 'estar' em um 'mundo virtual' - mas que é necessário, para explicar a experiência de worldness, incluir ambos como conceitos operacionais. Ryan (1994) acredita que a combinação entre imersão e interação serve para explicar a experiência de realidade de um usuário/jogador. Para a autora, "apreender um mundo como real é sentir-se inserido nele, ser capaz de interagir fisicamente com ele, e ter o poder de modificar tal ambiente. A conjunção de imersão e interatividade leva a um efeito conhecido como telepresença" (RYAN, 1994, apud KLASTRUP, 2003a, p. 295). 
Ao introduzir a idéia de (tele) presença, então, Klastrup (2003a, p. 295) articula os conceitos com as características de um 'mundo virtual', criando uma estrutura de entendimento para a relação usuário/jogador-mundo, que vai nos ajudar a compreender o porque de existir uma particularidade no processo de criação de identidades sociais, quando se tratando de tais ambientes.

Podemos considerar imersão como a criação de uma crença no mundo, onde o usuário conscientemente finge que tudo aquilo que acontece no 'mundo virtual' é 'real' ou 'verdadeiro', enquanto automaticamente interpreta eventos de acordo com seu significado in-game [...]. (Tele)Presença, então, é o sentimento de 'estar lá', experimentando que você é seu avatar, e as outras pessoas são seus respectivos avatares, através da interação com outros jogadores, da simulação do mundo e do sucesso da imersão. Relacionamento para com o mundo é o que emerge através da experiência da temporalidade do mundo; outros jogadores começam a importar para você e você começa a experimentar eventos relatáveis que fazem com que você se mantenha associado ao mundo porque você tem um interesse em completar a história no nível dos personagens individuais (KLASTRUP, 2003a, p. 295).

Deve-se observar, contudo, que Klastrup (2003a) enfoca aspectos narrativos em suas consideraçóes, mas sua análise não favorece o estudo dos aspectos lúdicos dos 'mundos virtuais', representados, neste trabalho, pela figura do 'círculo mágico'. Tais conceitos, apesar de estarem diretamente ligados à idéia da particularidade da formação identitária em tais ambientes, não devem ser equiparados com o conceito de 'círculo mágico' como explicado anteriormente.

\section{'Círculo Mágico': Agente Mediador dos Processos de Formação Identitária}

Como pudemos perceber, o processo de imersão - associado à experiência de mundo que Klastrup (2003a) chama de worldness - vivenciado pelos participantes de tais 'mundos virtuais' apresenta características que evidenciam um repertório que engloba algumas práticas sociais não usuais nas trocas efetivadas nas relaçóes cotidianas. Mesmo aquelas que poderiam ser identificadas como presentes no 'mundo real' parecem sofrer ligeiras mudanças, visando adaptaçôes às particularidades contextuais geradas pela 'lógica do jogo' adotada nestes mundos. Partindo de tais premissas, algumas questóes se fazem presentes: (1) Quais as diferenças em relação à possível imersão em relação a outros espaços e plataformas interacionais virtuais que não seguem a 'ógica do jogo'? (2) Quais os efeitos/repercussões na construção da identidade (em seus aspectos sócio-representacionais) derivados dessa diferenças? Temos como hipótese reflexiva que as particularidades associadas ao "círculo mágico" promovem o desenvolvimento de comportamentos sociais mais cambiantes, que, por sua vez, criam condiçóes favoráveis ao desenvolvimento de situaçôes experienciais singulares, configuradoras de identidades sociais mais fluidas.

Para o desenvolvimento de nosso argumento, cabe inicialmente uma exploração sobre a arena social destes 'mundos virtuais', tendo como referência seus mecanismos reguladores. A partir dos estudos de Lakatos e Marconi 
(1999) sobre as interaçóes como causadoras dos processos sociais, Recuero (2005), em sua análise da formação de redes sociais no ciberespaço, destaca a presença de três mecanismos que regem a dinâmica social produzida nos contatos interpessoais efetuados pelos navegantes: (a) processos cooperativos; (b) processos competitivos; e (c) processos conflitivos. Tal divisão parece-nos oportuna para analisar aspectos relacionais presentes nos 'mundos virtuais'. Os primeiros dizem respeito à atuação de indivíduos ou grupos visando o alcance de um objetivo comum. A cooperação nos ambientes virtuais pode ser atestada através de diversas manifestaçôes; desde aquela presente no processo de ajuda a um usuário iniciante (indicando caminhos, macetes, truques de sobrevivência no ambiente etc.), quanto às mais sofisticadas, derivadas de uma ética, construída e centrada na idéia de companheirismo que rege uma parte significativa de jogadores.

Os processos competitivos, por sua vez, representam os esforços de indivíduos ou grupos para a obtenção de aspiraçóes pessoais, diante de um ambiente que se mostra escasso de recursos materiais ou simbólicos que supram as necessidades desejadas. Assim, os participantes entram em um processo competitivo, buscando alcançar "melhores condiçóes de vida", bem como os benefícios sociais decorrentes desse processo de ascensão. Nos ambientes dos 'mundos virtuais', este processo costuma ser bastante explorado, haja vista que fomenta no usuário o desejo de galgar situaçôes sociais cada vez melhores, através da busca de status e reconhecimento (MALABY, 2006) por parte dos demais participantes, seja pela sua destreza técnica (matar dragóes, comandar um grupo de ataque às bases inimigas, comandar um pequeno exército de 25 ou 40 pessoas rumo a um objetivo que não pode ser alcançado com menos participantes que isso, etc), seja pela sua habilidade nas negociaçóes sociais para a obtenção de determinados objetivos (por exemplo: convencimento de que seus propósitos estratégicos são mais interessantes do que os de outros participantes, ou habilidades em lidar com diversas contingências que podem surgir no desenvolvimento do jogo).

Já os processos conflitivos seriam aqueles que radicalizam a disputa com o outro (seja este outro um indivíduo, outros grupos, ou outras nações). O clima passa a ser de hostilidade e o desejo é de eliminação do seu oponente. Todas as açóes são direcionadas para suplantar o outro, através de subjugação e humilhaçôes. Este mecanismo rege uma parte significativa da dinâmica social que se encontra nos 'mundos virtuais'. Ele promove ou fomenta a construção de grupos, alianças, estocagem de material para as disputas, a idéia de vencedores e vencidos, provocando uma autêntica movimentação e um eterno clima de guerra entre os participantes.

Dentro de uma perspectiva interacionista, temos uma vasta literatura (GOFFMAN, 1961, 1974, 1996; GERGEN, 1990, por exemplo) que aponta que a formação identitária dos indivíduos é derivada, em sua essência, das situaçóes vivenciadas nos diversos contextos sociais e da capacidade de representação dessas experiências, ou seja, é resultante dos aspectos sócio-representacionais construídos a partir da apropriação das particularidades das diversas 
práticas comunicativas e sociais oriundas do ambiente específico. Fato é que o contato com tais aspectos inerentes ao jogo transforma-se, então, num modificador de certos processos e comportamentos sociais, e conseqüentemente, das condiçôes produtoras da identidade social do avatar criado. A questão que se evidencia é se tal ocorrência revela apenas aspectos circunscritos ao personagem vivenciado no jogo, e portanto, sem nenhuma interferência na construção identitária do participante além dos limites do 'círculo mágico', ou se manifesta facetas experienciais que podem ser agregadas ao conjunto de elementos que formatam a base para configuração identitária do sujeito jogador.

Para o nosso olhar, a segunda opção interpretativa parece-nos mais plausível, haja vista que a presença do 'círculo mágico' ocasiona, de forma efetiva, ou a suspensão temporária dos referenciais sociais comumente utilizados na vida cotidiana (evidenciando assim a função delimitadora), ou o redimensionamento (quanto às suas importâncias e utilidades) desses mesmo referenciais (salientando desta forma a função mediadora), mas não inibe o aprendizado social de tais experiências. Em suma, o 'círculo mágico', vivenciado (de maneira delimitadora ou mediadora) pelos usuários dos 'mundos virtuais', possibilita a emergência de situaçóes sociais particulares, temporárias, mas que podem servir de base para exploração de territórios cognitivos e existenciais, enriquecendo assim o leque de experiências constituintes da identidade.

Interessante notar que, segundo diversos autores (TURKLE, 1997; RIBEIRO, 2003, dentre outros), existe a possibilidade de que haja uma identificação mais profunda, em algumas circunstâncias e devido aos motivos mais diversos, entre a identidade social e o papel desempenhado nos 'mundos virtuais', o que poderia vir a promover alteraçóes na estrutura de personalidade do indivíduo. Assim, alguns usuários poderiam vivenciar tấo intensamente as identidades virtuais de modo que as respectivas características poderiam ser gradativamente incorporadas à sua maneira habitual de ser no 'mundo real', 'fora do círculo mágico' (YEE, 2007). Em situaçôes mais extremas, isso ocasionaria até mesmo uma percepção de equivalência entre as duas esferas relacionais ('mundos virtuais' regidos pela 'lógica do jogo' e 'mundos reais'). Tal ocorrência, entretanto, náo pode ser vista apenas como uma ocorrência casual, derivada de um simples deslocamento de um ambiente social para outro, mas sim como resultante de um complexo processo de sucessivas identificaçóes provisórias, intercambiáveis, proporcionadas e ajustadas às diversas demandas e variáveis presentes na vivência das situaçóes contextuais.

\section{Considerações finais}

A partir da argumentação que foi traçada no decorrer do presente artigo, podemos, então, sugerir que há particularidades - e portanto pontos-chave que podem ser abordados em uma pesquisa mais extensa - no processo de criação de identidades sociais em 'mundos virtuais'. Nossa sugestão se baseia no fato de que em tais ambientes, além dos processos de mediação efetuados pelo computador na formação identitária - como apontam alguns estudos, como o de Ribeiro (2003) - existe outro fator de mediação que contribui para 
singularizar tal processo nos 'mundos virtuais'.

A presença inata de sistemas lúdicos (SALEN e ZIMMERMAN, 2003) com objetivos delineados em tais mundos exerce forte influência no modo pelo qual as relaçóes - e papéis - sociais se desenham no decorrer da experiência de mundo vivida pelo usuário/jogador. Através, portanto, do processo de imersão - e caminhando rumo ao processo de 'habitação' anteriormente explanado sob a lógica da worldness - o usuário/jogador é inserido dentro de uma ferramenta que pode lhe suprimir o espaço-tempo e transformar o ambiente virtual em extensão do real, no qual ele se relaciona através do avatar.

A supressão enfocada acima - efeito da inserção do sujeito no 'círculo mágico’ - media o relacionamento dos usuários, fazendo com que o processo de formação identitária aconteça imbricado ao tecido narrativo-lúdico, associando fatores técnicos, perceptuais, cognitivos e existenciais.

Curioso é perceber que apesar da fluidez inerente ao processo de construção identitária que acontece na comunicação mediada pelo computador, e apesar do fato de os 'mundos virtuais' também fazerem parte dessa lógica, seguindo a argumentação apontada durante o trabalho, a fluidez, embora aumentada, com relação às interaçôes face a face, ainda é, de certa forma, condicionada às situaçóes desenhadas pelos designers que projetam o ambiente - ou seja, condicionada à 'lógica do jogo', à presença do 'círculo mágico'.

Por fim, fazem-se necessárias pesquisas de cunho exploratório para fortalecer a argumentação e mapear dinâmicas e processos desenvolvidos na construção de relacionamentos sociais em tais ambientes - fomentando, assim, o estudo dos 'mundos virtuais' pelas várias ciências humanas e legitimando, dessa forma, a disciplina de estudo dos jogos. 


\section{Notas}

${ }^{1}$ Magic Circle, no original.

2 Jogo de terror lançado pela empresa japonesa Konami em 1999, cujos cuidados com os detalhes de cenário, a trilha sonora poluída e sombria, e as seqüências de horror e de ação/aventura acabaram por transformá-lo num clássico possuidor de vários outros títulos de continuaçóes e de uma adaptação para o cinema (Silent Hill, TriStar Pictures, 2006).

3 Pervasive Game desenvolvido em conjunto pelas empresas Avant Games e Persuasive Games em 2008, onde os jogadores confrontam os outros com elogios e declaraçóes de amor - a idéia principal é não saber quem está ou não está jogando, porque a comunicação é feita mediante celulares e dispositivos de comunicação móvel e não revela quem é quem - só a possível localização do jogador. http://www.avantgame. $\mathrm{com} /$

${ }^{4}$ Massive Multiplayer Online Role Playing Games - RPGs Multiusuário que se utilizam da Internet.

5 Anshe Chung é o avatar de Ailin Graef, chinesa radicada na Alemanha que se tornou literalmente milionária ao adentrar os negócios de corretagem, administração e desenvolvimento de propriedades online no 'mundo virtual' Second Life (Linden Lab, 2003).

${ }^{6}$ Mundo virtual controlado pelo Linden Lab, fenômeno de mídia e público em 2007 que teve uma violenta queda no número de usuários em 2008 (fonte: Linden Labs, http://lindenlab.com/). Para mais informaçôes, ver http://www.secondlife.com/.

${ }^{7}$ Multi-User Domains. Ambiente virtual multiusuário navegável via texto, desenvolvido primeiramente na década de 1980, na Universidade de Essex, no Reino Unido. Para mais informaçôes, visitar http://www.mud.co.uk/richard/.

8 2D e 3D são termos utilizados para referenciar animações em duas e três dimensões - existem, porém, algumas técnicas de perspectiva 2D, como a perspectiva isométrica, que simulam a animação em três dimensôes, como pode ser visto no 'mundo virtual' Ultima Online (Origin Systems, 1997).

9 Poética desenvolvida pela própria Klastrup (2003a) em sua tese de doutorado. Uma digressão mais complexa sobre este ponto estaria fora do eixo temático do presente artigo, contudo.

\section{Referências}

ALVES, Lynn. Game Over Jogos eletrônicos e violência. São Paulo: Futura. 2005.

AUGÉ, M. Não-lugares: introduçâo a uma antropologia da supermodernidade. Campinas: Papirus, 1994.

BAINBRIDGE, William Sims. The Scientific Research Potential of Virtual Worlds. In: Science 317, 472 (2007). Disponível em http://www.sciencemag.org. Acesso em 05/10/2007.

CAILLOIS, Roger. Les Jeux et Les Hommes. Le Masque et Le Vertige. Cher: Gallimard, 1961 (1967).

DIBBEL, Julian. The Life of the Chinese Gold Farmer. In: The New 
York Times, Disponível em http://www.nytimes.com/2007/06/17/ magazine/17lootfarmers-t.html. Acesso em Junho de 2007.

FALCÃO, Thiago. Reflexóes sobre a relação entre trabalho e lazer nos mundos sintéticos. Anais do $3^{\circ}$ Congresso de Estudantes de Pós-Graduação em Comunicação. Rio de Janeiro, RJ. 2008.

GERGEN, K.J. The saturated self: dilemmas of identity in contemporary life. New York: Basic Books, 1990.

GOFFMAN, E. A representação do eu na vida cotidiana. Petrópolis: Vozes, 1996.

Frame analysis: an essay on the organization of experience. New York: Harper \& Row, 1974.

Encounters: two studies in the sociology of interaction. New York: The Bobbs-Merrill Company, 1961.

HEEKS, Richard. Current Analysis and Future Research Agenda on "Gold Farming": Real World Production in Developing Countries for the Virtual Economies of Online Games. In: Development Informatics Working Paper Series, Paper n ${ }^{\circ} 32$. Disponível em http://www.sed.manchester.ac.uk/idpm/research/publications/wp/di/index.htm. Acesso em Agosto de 2008.

HUIZINGA, Johan. Homo Ludens: O Jogo como Elemento da Cultura. São Paulo: Perspectiva, 1950 (2001).

JUUL, Jesper. Half-Real. Video Games between Real Rules and Fictional Worlds. Cambridge: MIT Press, 2005.

KLASTRUP, Lisbeth. Towards a Poetics of Virtual Worlds. Tese de Doutorado apresentada à IT University of Copenhagen. Copenhague, 2003 a.

- A Poetics of Virtual Worlds. Artigo apresentado na conferência MelbourneDAC2003. Melbourne: 2003b. Em: http://hypertext.rmit. edu.au/dac/papers/. Acesso em 04/09/2008.

LAKATUS, Eva; MARCONI, Marina. Sociologia Geral. São Paulo: Atlas, 1999.

LALANDE, André. Vocabulaire Technique et Critique de la Philosophie. Paris: Librairie Félix Alcan, 1928.

LEMOS, André. Cidade e Mobilidade. Telefones Celulares, Funções PósMassivas e Territórios Informacionais. MATRIZes. Revista do Programa de Pós-Graduação em Ciências da Comunicação da Universidade de São Paulo, 2007a.

Mídia Locativa e Territórios Informacionais. Acessado em 2008.

Disponível em http:/www.facom.ufba.br/ciberpesquisa/andrelemos/ midia_locativa.pdf. Salvador, 2007b.

MALABY, Thomas. Parlaying Value: Capital In and Beyond Virtual Worlds. In: Games and Culture, Vol. 1, p. 141-163, 2006. 
MURRAY, Janet H. Hamlet on the Holodeck. The future of narrative in cyberspace. Cambridge: Mit Press, 1999.

RECUERO, Raquel. Comunidades Virtuais em Redes Sociais na Internet: Uma proposta de estudo. Ecompos, Internet, v. 4, n. Dez 2005, 2005.

RIBEIRO, José Carlos. Um olhar sobre a sociabilidade no ciberespaço: aspectos sócio-comunicativos dos contatos interpessoais efetivados em uma plataforma interacional on-line. Programa de Pós-Graduação em Comunicação e Cultura Contemporâneas da Universidade Federal da Bahia, Salvador, 2003. Tese de doutorado.

;BRUNET, Karla e FALCÃO, Thiago. Comunicaçâo Móvel e Jogos em Espaços Hibridos. Anais do XXXI Congresso Brasileiro de Ciências da Comunicação. Natal, RN, 2008.

RYAN, Marie-Laure. Narrative as Virtual Reality: Immersion \& Interactivity in Literature \& Electronic Media. Baltimore: Johns Hopkins University Press, 2001.

SALEN, K. e ZIMMERMAN, E. Rules of Play: Game Design Fundamentals. Cambridge: MIT Press, 2003.

TURKLE, S. A vida no ecrä: a identidade na era da internet. Lisboa: Relógio D’água, 1997.

YEE, Nick. The Proteus Effect. Behavioral Modification via Transformations of the Digital-Self Representation. Tese de Doutorado apresentada ao Departamento de Comunicação da Universidade de Stanford. Stanford, 2007. 